\title{
Fermentation and Hydrogen Metabolism Affect Uranium Reduction by Clostridia
}

\author{
Weimin Gao ${ }^{1}$ and Arokiasamy J. Francis ${ }^{2,3}$ \\ ${ }^{1}$ Center for Biosignatures Discovery Automation, Biodesign Institute, Arizona State University, Tempe, AZ 85287, USA \\ ${ }^{2}$ Division of Advanced Nuclear Engineering, Pohang University of Science and Technology, Pohang 790-784, Republic of Korea \\ ${ }^{3}$ Environmental Sciences Department, Brookhaven National Laboratory, Upton, NY 11973, USA
}

Correspondence should be addressed to Weimin Gao; weimin.gao.2@asu.edu

Received 12 December 2012; Accepted 19 January 2013

Academic Editors: V. P. Bulgakov and M. Rossi

Copyright (C) 2013 W. Gao and A. J. Francis. This is an open access article distributed under the Creative Commons Attribution License, which permits unrestricted use, distribution, and reproduction in any medium, provided the original work is properly cited.

\begin{abstract}
Previously, it has been shown that not only is uranium reduction under fermentation condition common among clostridia species, but also the strains differed in the extent of their capability and the $\mathrm{pH}$ of the culture significantly affected uranium(VI) reduction. In this study, using HPLC and GC techniques, metabolic properties of those clostridial strains active in uranium reduction under fermentation conditions have been characterized and their effects on capability variance of uranium reduction discussed. Then, the relationship between hydrogen metabolism and uranium reduction has been further explored and the important role played by hydrogenase in uranium(VI) and iron(III) reduction by clostridia demonstrated. When hydrogen was provided as the headspace gas, uranium(VI) reduction occurred in the presence of whole cells of clostridia. This is in contrast to that of nitrogen as the headspace gas. Without clostridia cells, hydrogen alone could not result in uranium(VI) reduction. In alignment with this observation, it was also found that either copper(II) addition or iron depletion in the medium could compromise uranium reduction by clostridia. In the end, a comprehensive model was proposed to explain uranium reduction by clostridia and its relationship to the overall metabolism especially hydrogen $\left(\mathrm{H}_{2}\right)$ production.
\end{abstract}

\section{Introduction}

Subsurface contamination by radionuclides and toxic metals is a major problem throughout the U.S. Department of Energy's (DOE's) complex; uranium contamination evokes particular environmental concern due to the high solubility and mobility of its oxidized form, U(VI). As physically removing the contaminated material is financially prohibitive, we need innovative, cost-effective in situ stabilization technologies that exploit the processes of natural attenuation. Recently, researchers at some DOE sites have assessed the microbial stabilization of actinides $(\mathrm{U}, \mathrm{Pu}$, and $\mathrm{Np}$ ) and fission products $(\mathrm{Tc})$ in subsurface environments, as in the uranium mill tailing remedial action (UMTRA) site in Rifle, CO (http://www.gjem.energy.gov/moab/) and at the Oak Ridge Field Research Centre (ORFRC) at Oak Ridge, TN (http://www.esd.ornl.gov/orifrc/). A wide variety of bacteria, including Desulfovibrio, Geobacter, and Shewanella, can couple the oxidation of organic compounds to the reduction of $\mathrm{U}(\mathrm{VI})$ and thus reductively precipitate uranium in its reduced form $U(I V)$ [1-3]. Investigators have explored the mechanisms of uranium(VI) reduction by anaerobic bacteria [4-6].

Clostridia are anaerobic fermenting bacteria. They are gram-positive, spore-forming bacilli found in soils, sediments, wastes, and in the normal intestinal flora of humans and animals. They play a major role in decomposing a wide variety of organic compounds [7]. The fermentation industry uses them widely to produce solvents and biofuels, including acetone, ethanol, butanol, and hydrogen $[8,9]$. Some members of the class also are capable of non symbiotic nitrogen $\left(\mathrm{N}_{2}\right)$ fixation [10], and others can reductively synthesize acetate from carbon dioxide $\left(\mathrm{CO}_{2}\right)$ via the Wood-Ljungdahl pathway [11]. Unlike those anaerobic respiratory bacteria, clostridia classically were viewed as obligate anaerobic, fermentative bacteria, although recent evidence showed that 
some strains of this group are tolerant of oxygen to some extent $[12,13]$.

Previously, it was showed that Clostridium sp. BC1 (ATCC 53464) and C. sphenoides (ATCC 19403) can reduce uranylnitrate, -acetate, and -citrate complexes, as well as complexes of other metals [14-16]. We then argued that if the reduction of uranyl compounds could be a general property of clostridia. We have further found that not only is this ability common among more clostridia species, but that also the strains differed in the extent of their capability. The $\mathrm{pH}$ of the culture significantly affected uranium(VI) reduction, with pH 5-6 being the optimal one in most cases. Among the strains tested, Clostridium sp. $\mathrm{BCl}$ showed the highest rate of $\mathrm{U}(\mathrm{VI})$ reduction [17]. Apparently, the evidence suggested that clostridia is one of the major players in uranium reduction in situ in an acidic $(\mathrm{pH}=4)$ uranium-mine pit water $[18,19]$, at a military facility near Chesapeake Bay, Maryland, United States [20], as well as at the ORFRC at Oak Ridge, TN [21].

In this study, using HPLC and GC techniques, we have continually characterized metabolic properties of those clostridial strains active in uranium reduction under fermentation conditions and discussed their effects on performance of uranium reduction. We also demonstrated that hydrogen metabolism could play an important role in uranium(VI) and iron(III) reduction by clostridia. In the end, we proposed a comprehensive model to explain molecular mechanisms of uranium reduction by clostridia and its relationship to the overall metabolism especially hydrogen $\left(\mathrm{H}_{2}\right)$ production.

\section{Materials and Methods}

2.1. Bacterial Strains and Media. Clostridium sp. BC1 (ATCC 53464) was isolated in our laboratory [22]. We purchased C. sphenoides (ATCC 19403), C. acetobutylicum (ATCC 824), and C. pasteurianum (ATCC 7040) from the American Type Culture Center (ATCC). All strains can ferment glucose, but only $C$. sphenoides can metabolize citric acid as the sole carbon and energy source. All strains were grown anaerobically and maintained in the mineral salts medium, herein called MSM medium, containing per liter: glucose $5.0 \mathrm{~g}$, $\mathrm{NH}_{4} \mathrm{Cl} 0.5 \mathrm{~g}$, glycerol phosphate $0.3 \mathrm{~g}, \mathrm{MgSO}_{4} \cdot 7 \mathrm{H}_{2} \mathrm{O} 0.2 \mathrm{~g}$, $\mathrm{CaCl}_{2} \cdot 2 \mathrm{H}_{2} \mathrm{O} 0.5 \mathrm{~g}$, peptone $0.1 \mathrm{~g}$, and yeast extracts $0.1 \mathrm{~g}$, $6.25 \mathrm{~mL}$ of $1.6 \mathrm{mM} \mathrm{FeSO} \cdot 7 \mathrm{H}_{2} \mathrm{O}$, at $\mathrm{pH}$ 6.8. The medium was prepared as follows. We dissolved all the ingredients except $\mathrm{FeSO}_{4}$ to about $1000 \mathrm{~mL}$ in deionized water in a 2000 Erlenmeyer flask and prereduced by boiling and purging with nitrogen gas for 20 minutes. After allowing the solution to cool, we placed the flask in an anaerobic glove box (95\% $\mathrm{N}_{2}, 5 \% \mathrm{H}_{2}$ ) and then added to the medium $6.25 \mathrm{~mL}$ of $1.6 \mathrm{mM}$ prereduced $\mathrm{FeSO}_{4} \cdot 7 \mathrm{H}_{2} \mathrm{O}$ (prepared by dissolving $90 \mathrm{mg}$ ferrous sulfate in $200 \mathrm{~mL}$ of prereduced deionized water and adding $0.5 \mathrm{~mL}$ concentrated $\mathrm{HCl}$ ) and made up the total volume to $1000 \mathrm{~mL}$ with prereduced deionized water. The $\mathrm{pH}$ was adjusted to 6.8 before dispensing $40 \mathrm{~mL}$ aliquots of the medium into $60 \mathrm{~mL}$ serum bottles, fitted with butyl rubber stoppers, then crimp-sealing them with aluminum caps before autoclaving. C. sphenoids (ATCC19403) was also cultured in Simmons Citrate medium (SCM); all materials and their preparation were exactly the same as for the MSM medium, except that we substituted glucose with $8.2 \mathrm{~g}$ sodium citrate. To stabilize the $\mathrm{pH}$ of the culture, as needed, we added $50 \mathrm{mM}$ PIPES ( $\mathrm{pH} 6.8$ ) or $50 \mathrm{mM}$ MES ( $\mathrm{pH} 6.2$ ) to the medium. The bacterial cultures were grown at $26^{\circ} \mathrm{C}$ in the dark on a rotary shaker agitated at $100 \mathrm{rpm}$. Total gas production in the headspace of the sample was measured by a pressure transducer with a needle (Model 665-D/030, Wallace and Tiernan) [22]. We removed four-milliliter aliquots of the culture to determine bacterial growth, change in $\mathrm{pH}$, and production of organic acid metabolites. The growth of the bacterium was measured by recording the turbidity of the medium at $600 \mathrm{~nm}$, using a Bausch and Lomb Spectronic 20 spectrophotometer.

2.2. Uranium(VI) Solution Preparation. The U(VI)-nitrate (Uranyl nitrate) stock solution $(0.5 \mathrm{M})$ was made by dissolving solid $\mathrm{UO}_{2}\left(\mathrm{NO}_{3}\right)_{2}$ into prereduced deionized water. The exact concentration of uranium(VI) stock was calibrated using a KPA machine (Kinetic Phosphorescence Analyzer, Chemchek Instruments, Inc.) that was manipulated according to the manufacturer's instruction. For the $10 \mathrm{mM} \mathrm{U}(\mathrm{VI})$ nitrate stock solution, $5 \mathrm{~mL}$ of prereduced deionized water was added to a beaker along with $0.25 \mathrm{~mL}$ of $0.5 \mathrm{M} \mathrm{U}(\mathrm{VI})$ nitrate, the $\mathrm{pH}$ adjusted to 6.1 with $\mathrm{NaOH}$, and the solution diluted to $10 \mathrm{~mL}$ for a final concentration of $10 \mathrm{mM}$. The complexes were stored in the dark and then readjusted to $\mathrm{pH} 6.1$ after 24 hours, and filter-sterilized $(0.45 \mu \mathrm{m})$ into a vacutainer tube. $10 \mathrm{mM} \mathrm{U}(\mathrm{VI})$-citrate stock solution was made by mixing the $0.5 \mathrm{M} \mathrm{U}(\mathrm{VI})$-nitrate solution with citrate acid at the molar ratio of $1: 1$ as described below. Briefly, $0.5 \mathrm{~mL}$ of prereduced citric acid solution $(200 \mathrm{mM})$ was added to a beaker in the gloved box along with $0.2 \mathrm{~mL}$ of $0.5 \mathrm{M} \mathrm{U}(\mathrm{VI})$-nitrate. The $\mathrm{pH}$ was adjusted to 6.1 with prereduced $\mathrm{NaOH}$ and diluted to $10 \mathrm{~mL}$ for a final concentration of $10 \mathrm{mM}$.

2.3. Uranium(VI) Reduction Assay. Ten milliliters of the culture at the late-log phase was transferred to anaerobic preautoclaved serum bottle $(20 \mathrm{~mL})$, and then $0.1 \mathrm{~mL}$ of $10 \mathrm{mM} \mathrm{U}(\mathrm{VI})$-nitrate solution added via a 1-mL syringe with a needle. To determine the U(VI) concentration over time, aliquots of 0.1 to $0.2-\mathrm{mL}$ of the bacterial culture were taken from the serum bottle, $5 \mu \mathrm{L}$ of the culture diluted in $2 \mathrm{~mL}$ deionized water and immediately analyzed for U(VI) by KPA.

To assess the effect of $\mathrm{pH}$ on $\mathrm{U}(\mathrm{VI})$ reduction by Clostridia, ten milliliter aliquots of the late-log growth phase of the bacterial culture were adjusted to the required $\mathrm{pH}$ values using $1 \mathrm{~N} \mathrm{NaOH}$ or $\mathrm{HCl}$.

2.4. UV-Vis Analysis of Uranium(VI) and Uranium(IV). The UV-vis (ultraviolet-visible) spectrophotometry was used for obtaining absorption spectra of both uranium(VI) and uranium(IV). A Hewlett Packard Model 8453 UV-VIS spectrometer was used for this purpose. The sample was prepared as follows: after completing the uranium reduction assay described above, the total leftover culture in serum bottle was collected into a centrifuge tube in the glove box. Then, its $\mathrm{pH}$ was adjusted to 11 using $1 \mathrm{~N} \mathrm{NaOH}$, and the culture 
centrifuged at $10000 \mathrm{rpm}$ for 10 minutes, the supernatant discarded, and the pellet was resuspended in 2-mL $10 \mathrm{mM}$ citric acid solution to extract the uranium species. The solution was filtered through a $0.45 \mu \mathrm{m}$ membrane and then the filtrate was analyzed by UV-VIS spectrophotometry to determine the absorption spectra of both uranium(VI) and uranium(IV).

2.5. Metabolite Profiling. The fermentation products, including organic acids and gases, were analyzed by high performance liquid chromatography (HPLC) and gas chromatography (GC). The HPLC unit consisted of a Shimadzu SCL10A System Controller, a SIL-10A autoinjector, and a LC10AS liquid chromatograph. The culture sample, filtered through a $0.45 \mu \mathrm{m}$ filter, was analyzed by HPLC for organic acids using an SPD-10A UV-vis detector at $210 \mathrm{~nm}$; for glucose, we employed a RID-6A refractive index detector (Shimadzu). A SRI 8610C gas chromatograph fitted with a thermal conductivity detector was used to analyze the $\mathrm{H}_{2}$ produced through fermentation.

\section{Results}

3.1. Growth of Bacteria, Gas Production in the Headspace, Changes in $\mathrm{pH}$, and Metabolite Profile. We determined the rate of growth, changes in $\mathrm{pH}$ of the media, and gas production of the four clostridia strains cultured in MSM or SCM. We also analyzed the extent of consumption of the carbon source and the metabolic products from the strains. Figure 1 shows the highest cell density (i.e., rate of growth) in Clostridium sp.; this strain also generated the most gas, even after entering stationary phase, while all other strains stopped producing gas at the stationary phase. Indeed, the growth of all other isolates in the MSM medium was poorer. The $\mathrm{pH}$ fell from 6.8 to below 3.0 in Clostridium sp., C. acetobutylicum, and C. pasteurianum, and to 4.2 in C. sphenoides. This drop probably reflected the production of organic acids (the drop might be caused also by changing the activity of H-ATPase). GC analysis of the headspace gas showed that the maximum percentage of hydrogen $\left(\mathrm{H}_{2}\right)$ produced by Clostridium sp., C. acetobutylicum, C. pasteurianum, and C. sphenoides, respectively, was about $75 \%, 60 \%, 45 \%$, and 25\% (Figure 1). Growth of C. sphenoides in SCM medium containing citrate as the carbon source and comparing it with that in MSM medium revealed no significant differences in its maximum cell density and gas production (Figure 1). However, the medium's $\mathrm{pH}$ slightly increased from near neutral to around $\mathrm{pH} 7.8$, due to the concurrent consumption of citric acid (Figure 1).

We tested alternative carbon sources including sucrose and glycerol and found that neither improved the growth of these strains (data not shown). However, growing the clostridia in media supplemented with a $\mathrm{pH}$ buffer to stabilize $\mathrm{pH}$ alleviated the drop in $\mathrm{pH}$ due to the production of organic acid during glucose fermentation (Figure 2). When cultured in MSM medium supplemented with $50 \mathrm{mM}$ PIPES ( $\mathrm{pH}$ 6.8), $\mathrm{pH}$ of the medium reached around 5 to 6 by the late-log phase of growth for Clostridium sp., C. acetobutylicum, and
C. pasteurianum; supplementation with $50 \mathrm{mM}$ MES ( $\mathrm{pH}$ 6.2) caused the final $\mathrm{pH}$ of these cultures to reach 4 to 5. Furthermore, the $\mathrm{pH}$-buffered medium affected the growth kinetics and final cell density of the strains. Compared to growth in MSM medium without $\mathrm{pH}$ buffer, Clostridium sp. grew much slower initially when the medium was buffered to $\mathrm{pH}$ 6.8, although growth later accelerated and it reached the stationary phase at the same time (40 hours) and at the same optimal density $\left(\mathrm{OD}_{600 \mathrm{~nm}}=0.8\right)$. In contrast, Clostridium $\mathrm{sp}$. grew much faster in the medium buffered to $\mathrm{pH}$ 6.2, reaching the stationary phase 20 hours earlier at the same optimal density $\left(\mathrm{OD}_{600 \mathrm{~nm}}=0.8\right)$ (Figure 2).

The growth of $C$. acetobutylicum was higher in medium buffered at $\mathrm{pH}$ 6.2, and it attained the stationary stage in about 10 hours earlier than that of unbuffered medium. By contrast, in MSM buffered to $\mathrm{pH} \mathrm{6.8,} \mathrm{like} \mathrm{Clostridium} \mathrm{sp.,} \mathrm{its} \mathrm{growth}$ was much lower at the first 15 hours; thereafter, it reached the same level as that in unbuffered culture. Addition of buffers did not result in an increase in final cell density (Figure 2). The growth of C. pasteurianum increased in the $\mathrm{pH} 6.8$ and 6.2 adjusted buffered medium (Figure 2). The similar trends also occurred in the production of total gas by these strains (Figure 2).

Analysis of culture medium by HPLC showed that all these strains produced acetic acid and butyric acid (Figure 3 ). Glucose consumption and production of the organic acids were influenced by the initial $\mathrm{pH}$ of the medium; buffered medium at $\mathrm{pH} 6.2$ showed the rapid glucose consumption and production of acetic and butyric acids. The maximum consumption of glucose was concurrently accompanied by reaching the production peak of butyric acid in all strains assayed. In the case of Clostridium sp., glucose consumption reached $100 \%$ completion at 50,30, and $40 \mathrm{~h}$ in unbuffered, buffered medium at $\mathrm{pH} 6.2$ and 6.8, respectively. Concurrently, butyric acid production attained its peak at the same time point as that of $100 \%$ glucose consumption, and the highest concentration measured was $13.5,11.5$, and $10.5 \mathrm{mM}$ in unbuffered, buffered medium at $\mathrm{pH} 6.2$ and 6.8 , respectively. By contrast, acetic acid production reached its peak at 40 , 30 , and $30 \mathrm{~h}$ and the corresponding concentration measured was $8.5,14$, and $9.5 \mathrm{mM}$, in unbuffered, buffered medium at $\mathrm{pH} 6.2$ and 6.8, respectively. Similarly, in the case of C. acetobutylicum, maximum consumption of glucose was reached at 50,26, and $40 \mathrm{~h}$ in unbuffered, buffered medium at pH 6.2 and 6.8, respectively. At these time point, butyric acid production attained its peak and the concentration measured was $9.5,13.5$, and $12 \mathrm{mM}$ in unbuffered, buffered medium at $\mathrm{pH} 6.2$ and 6.8, respectively. Acetic acid production reached its peak at 42,26 , and $30 \mathrm{~h}$ and the corresponding concentration measured was $6,8.5$, and $8 \mathrm{mM}$ in unbuffered, buffered medium at $\mathrm{pH} 6.2$, and 6.8, respectively. In the case of $C$. pasteurianum, maximum consumption of glucose was approached at 50,26, and $30 \mathrm{~h}$ in unbuffered, buffered medium at $\mathrm{pH} 6.2$ and 6.8, respectively. At the same time point, butyric acid production attained its peak and the concentration measured was $7.5,11.5$, and $10.5 \mathrm{mM}$ in unbuffered, buffered medium at $\mathrm{pH} 6.2$ and 6.8, respectively. For this strain, acetic acid production reached its peak at 42,26 , and $30 \mathrm{~h}$, and the corresponding concentration measured was 5 , 


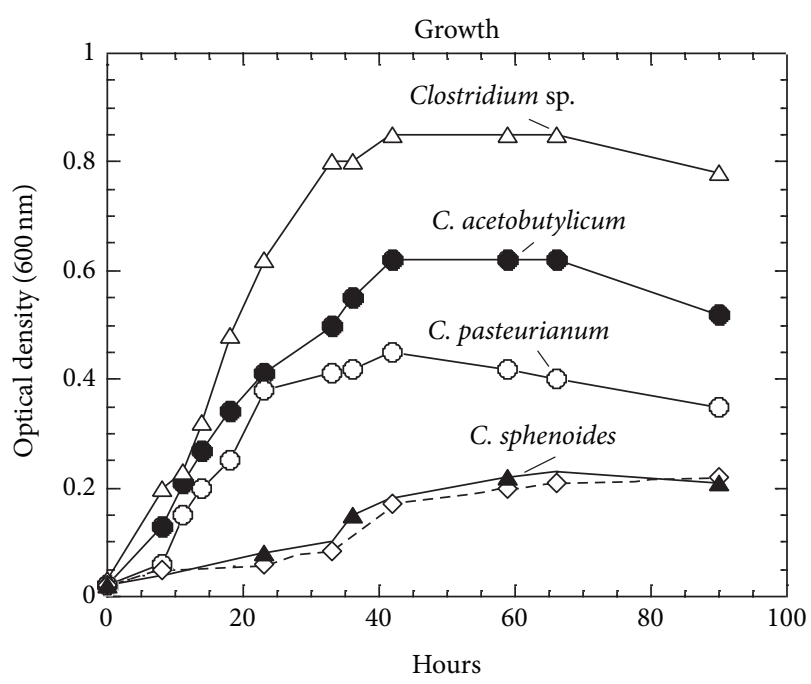

(a)

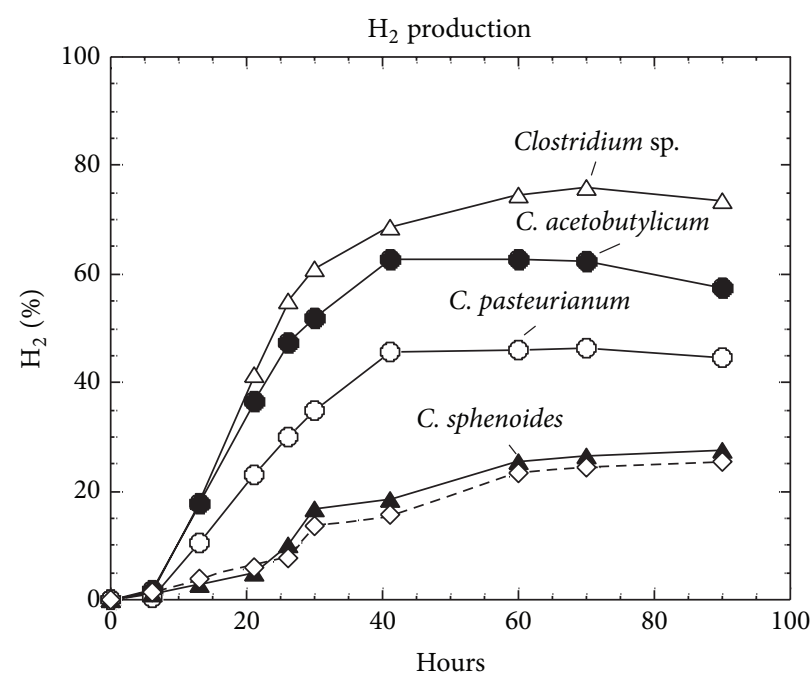

(c)

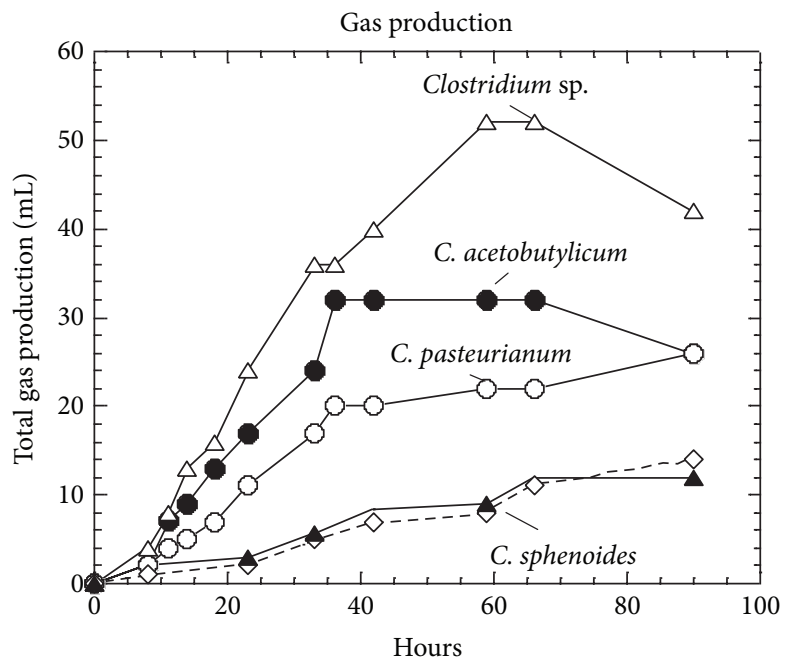

(b)

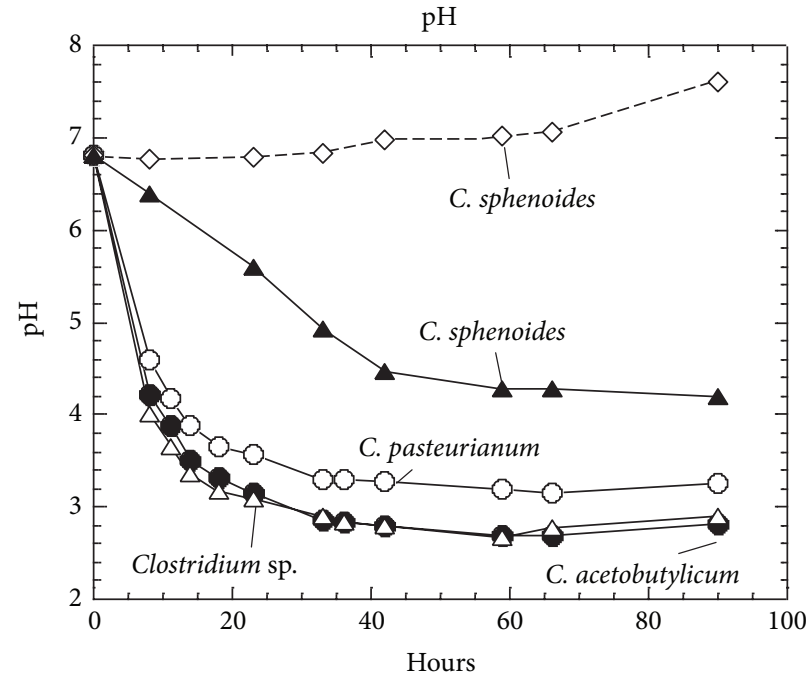

(d)

FIGURE 1: Growth, total gas production, hydrogen production, and $\mathrm{pH}$ change in Clostridia. Note that all four strains including Clostridium sp., C. acetobutylicum, C. pasteurianum, and C. sphenoides were grown in MSM medium, while C. sphenoides was also in SCM medium (marked with dashed line).

14.5 , and $11.5 \mathrm{mM}$ in unbuffered, buffered medium at $\mathrm{pH} 6.2$ and 6.8 , respectively.

C. sphenoides showed no increase in cell density and growth after adding $\mathrm{pH}$ buffers to either MSN or SCM medium (data not shown). Further, HPLC measurements revealed that this strain only generated acetic acid when cultured in both SCM and MSM (data not shown).

We also observed that, when the medium was buffered at pH 7.2 and above (7.5), Clostridium sp. did not grow; the other three strains grew slowly at $\mathrm{pH} 7.2$, but did not grow above 7.5 (data not shown).

3.2. Hydrogen $\left(\mathrm{H}_{2}\right)$ Consumption Results in $\mathrm{U}(\mathrm{VI})$ and $\mathrm{Fe}(\mathrm{III})$ Reduction of Clostridia. We demonstrated that gaseous hydrogen, in the presence of clostridia cells, could result in both $\mathrm{U}(\mathrm{VI})$ and $\mathrm{Fe}(\mathrm{III})$ reduction (Figure 4). Cultured clostridia cells were spun down, washed, and then resuspended in carbon-free MSN medium in a serum bottle under anaerobic conditions. Thereafter, headspace gases were replaced with pure hydrogen or nitrogen gas. When hydrogen was provided as the headspace gas, either uranium(VI) or iron(III) reduction occurred in the presence of whole cells of Clostridium sp. BCl. This is in contrast to experiments which used nitrogen as the headspace gas. Without whole cells, hydrogen alone did not result in either uranium(VI) or iron(III) reduction, suggesting that hydrogenase indeed mediated both the uranium(VI) and iron(III) reduction using hydrogen as an electron donor (Figures 4(a) and 4(b)). Both the gas pressure and $\mathrm{pH}$ in the bottle containing bacterial cells with hydrogen decreased after overnight incubation. Using 

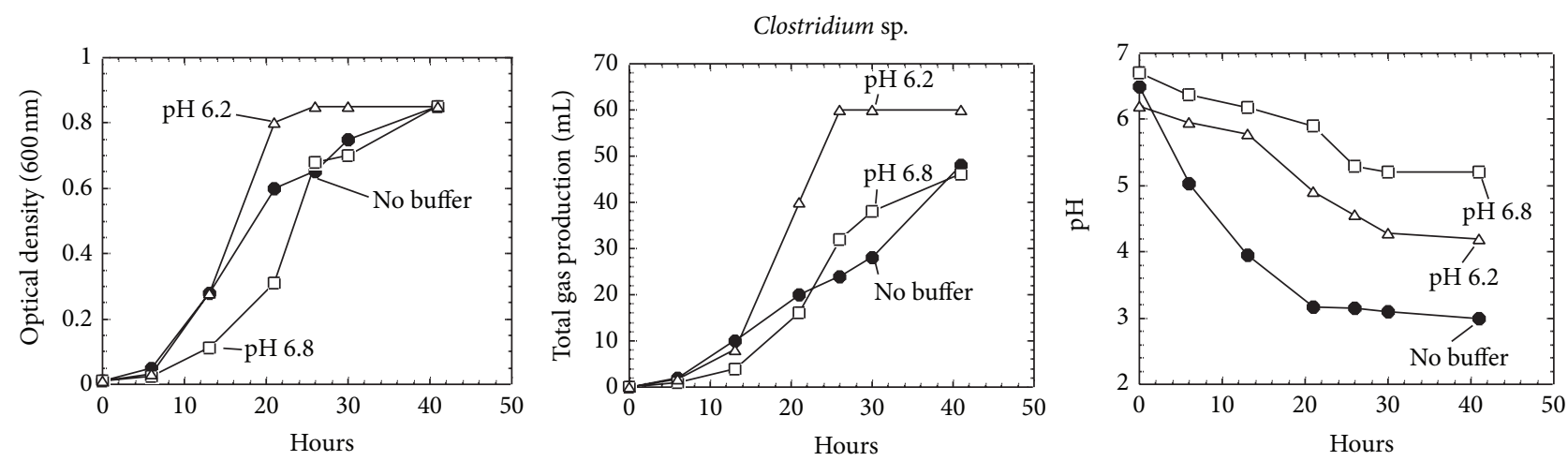

(a)
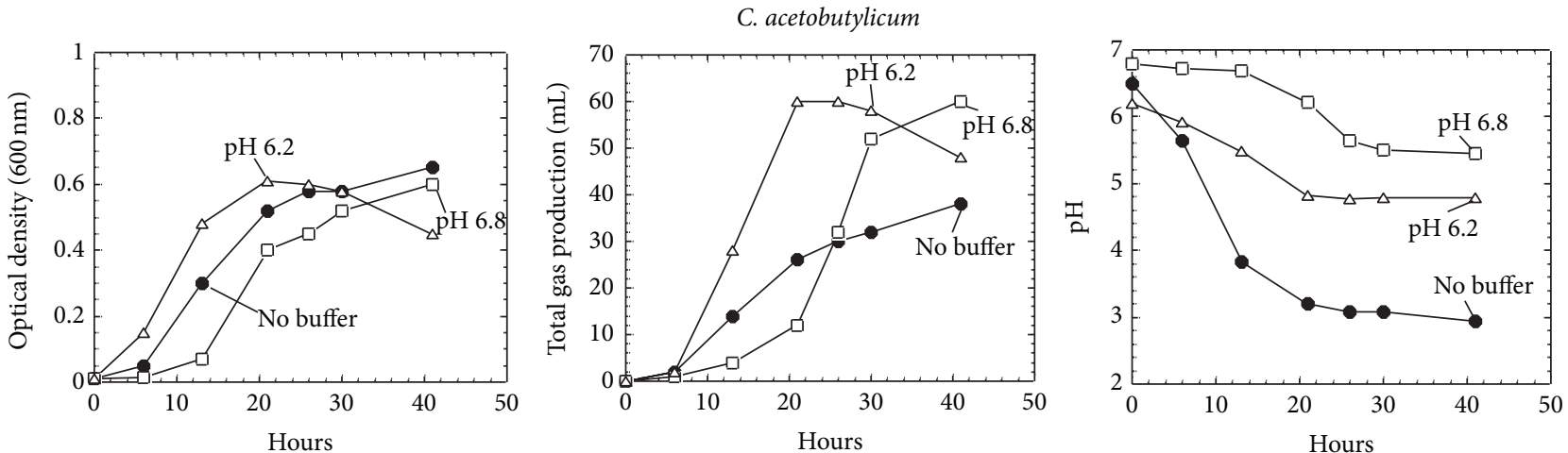

(b)
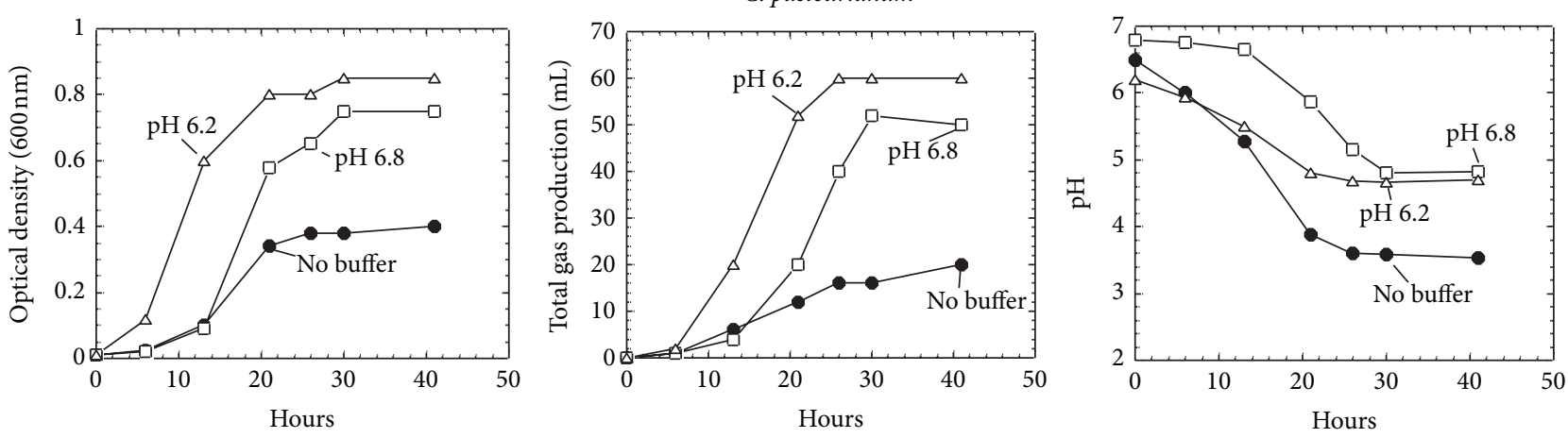

(c)

FIGURE 2: Growth, headspace gas production, and $\mathrm{pH}$ change in clostridia strains cultured in MSM medium supplemented with and without $\mathrm{pH}$ buffer. The initial $\mathrm{pH}$ of the medium is indicated.

other Clostridia strains as testing material, similar results were also obtained (data not shown).

3.3. Copper(II) Inhibits Uranium Reduction. We found that $\mathrm{Cu}(\mathrm{II})$ strongly inhibit $\mathrm{U}(\mathrm{VI})$ reduction of Clostridia. When concentration of $\mathrm{Cu}(\mathrm{II})$ reached $20 \mathrm{mM}$, the $\mathrm{U}(\mathrm{VI})$ reduction activity by $\mathrm{BC} 1$ was $100 \%$ inhibited (Figure 5 ). The inhibition effect of $\mathrm{Cu}(\mathrm{II})$ is not relevant with the $\mathrm{U}$ (VI) form used $\left(\mathrm{UO}_{2}\left(\mathrm{NO}_{3}\right)_{2}\right.$ or $\mathrm{U}(\mathrm{VI})$-citric acid complex) (data not shown). In terms of inhibition effect on uranium reduction, no difference was observed between simultaneous and stepwise addition of $\mathrm{Cu}(\mathrm{II})$ and $\mathrm{U}(\mathrm{VI})$ into assay (data not shown), suggesting that the inhibition effect of $\mathrm{Cu}(\mathrm{II})$ is immediate and most likely occurs at enzymatic level.

3.4. Iron Deficiency Affects U(VI) Reduction by Clostridia. Clostridium. Cells cultured in iron deficient media compromised its capability for uranium reduction (Figures 6(a) and 6(b)). Compared with iron-rich medium which contained $10 \mu \mathrm{M} \mathrm{Fe}(\mathrm{II}), \mathrm{BCl}$ cells cultured in iron-depleted medium containing $<0.01 \mu \mathrm{M}, \mathrm{Fe}(\mathrm{II})$ performed much poorer in $\mathrm{U}(\mathrm{VI})$ reduction to $\mathrm{U}(\mathrm{IV})$ during the time period of assay. 

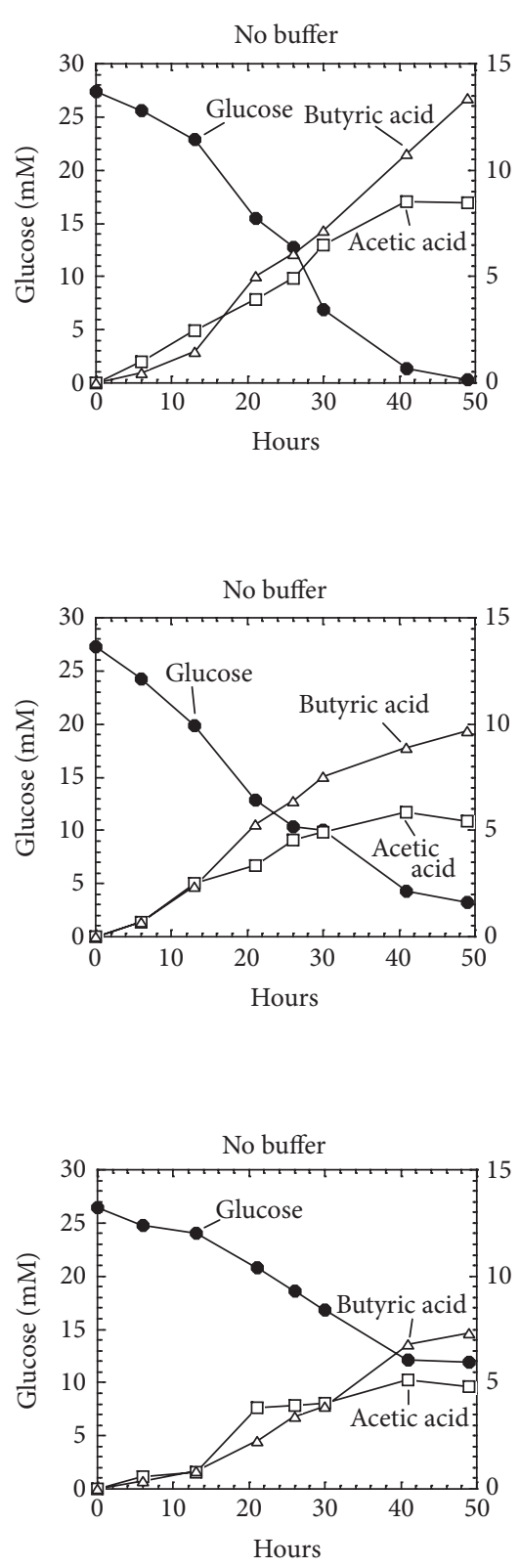

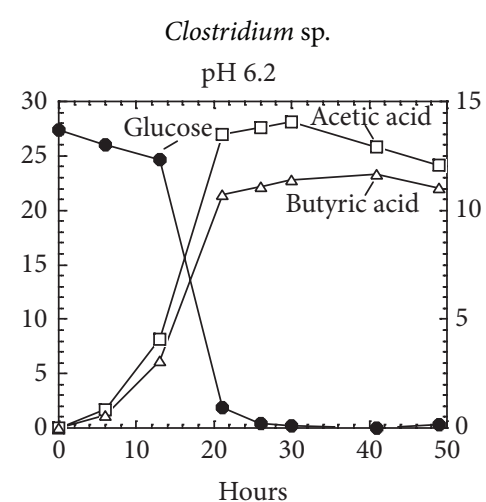

(a)

C. acetobutylicum

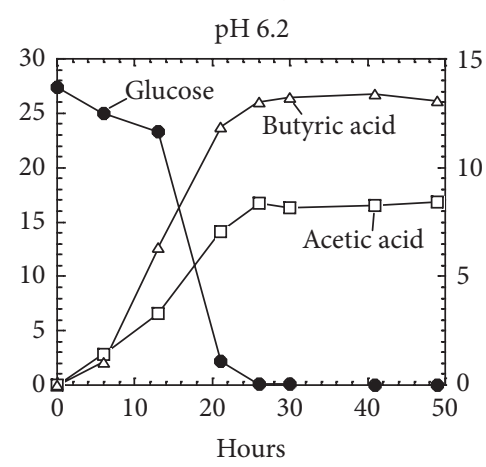

(b)

\section{C. pasteurianum}

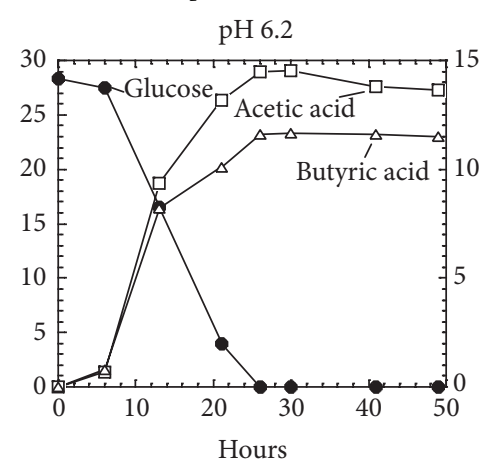

(c)
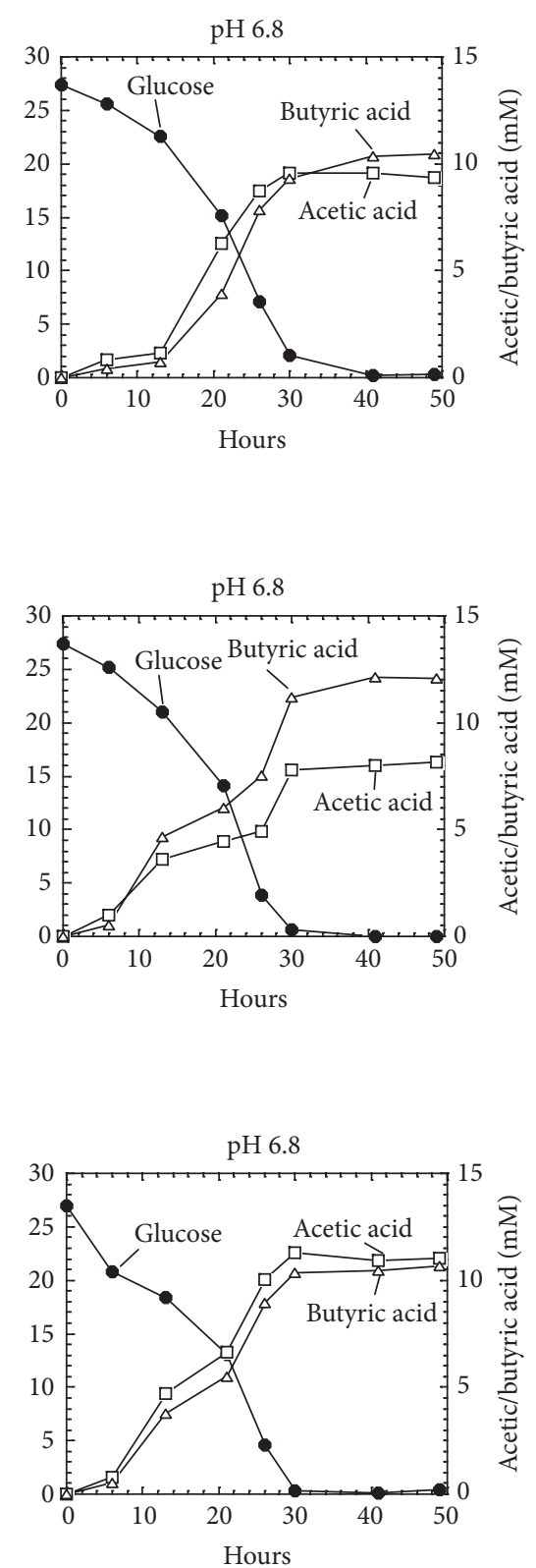

FIGURE 3: Glucose consumption and organic acid production by Clostridia grown in MSM medium supplemented with and without pH buffer.

\section{Discussion}

Previously, we demonstrated that Clostridium sp. $\mathrm{BCl}$ and $C$. sphenoides can reduce uranium $[15,22]$. Later, we expanded this list to C. acetobutylicum and C. pasteurianum that were identified many years ago and have been widely used in basic and applied studies [17]. For instance, ATCC 824, the type strain of species C. acetobutylicum, was isolated in 1924 from garden soil in Connecticut [23] and is one of the best-studied solventogenic clostridia used to develop an industrial starch-based acetone, butanol, and ethanol (ABE) fermentation process [8]. The entire genome of that strain was sequenced already [24]. Our study found that both $C$. acetobutylicum and C. pasteurianum can reduce uranium so bolstering our previous conclusion that this ability is a common phenomenon among clostridia bacteria [17]. We demonstrated that not only all of the clostridia tested are able to reduce $\mathrm{U}(\mathrm{VI})$ to $\mathrm{U}(\mathrm{IV})$, but also there are considerable differences in the extent of their ability to do so [17]. The extent for uranium reduction varies among clostridia strains and that $\mathrm{pH}$ of medium strongly influences the dynamic process of uranium reduction. Without a buffer supplement, 


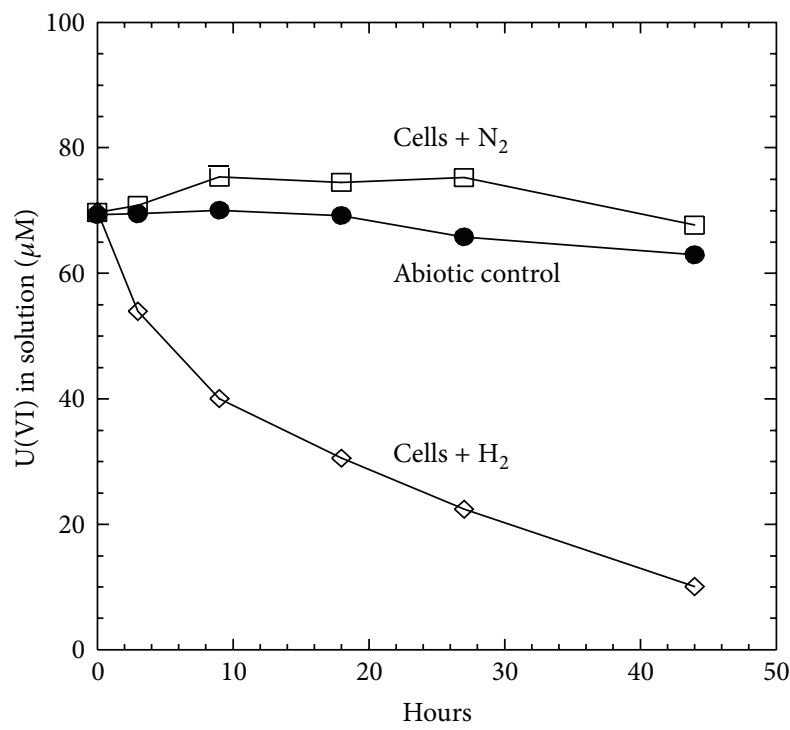

(a)

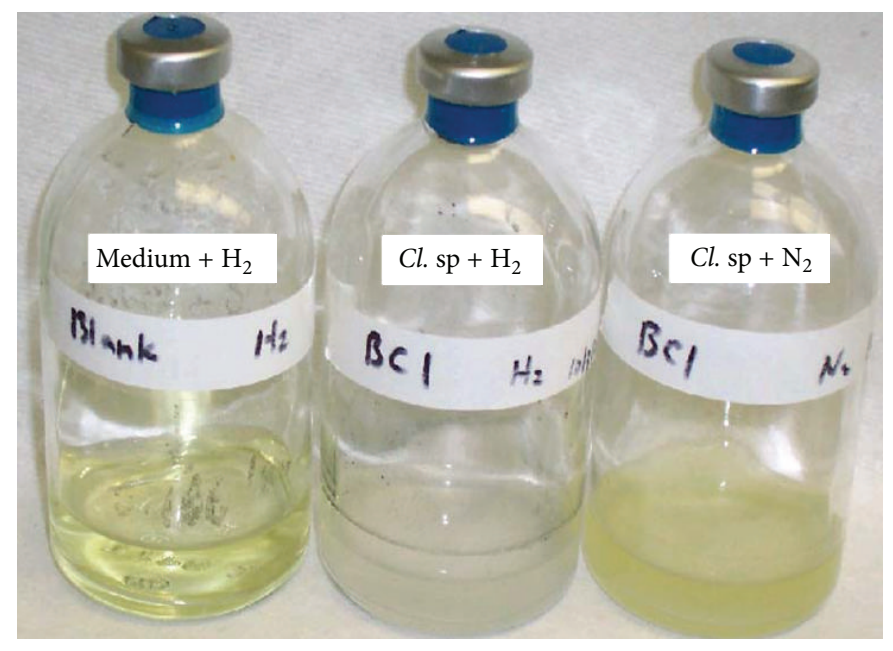

(b)

FIgURE 4: Hydrogen-driven reduction of U(VI) (a) and Fe(III) (b) by Clostridium sp. BC1.

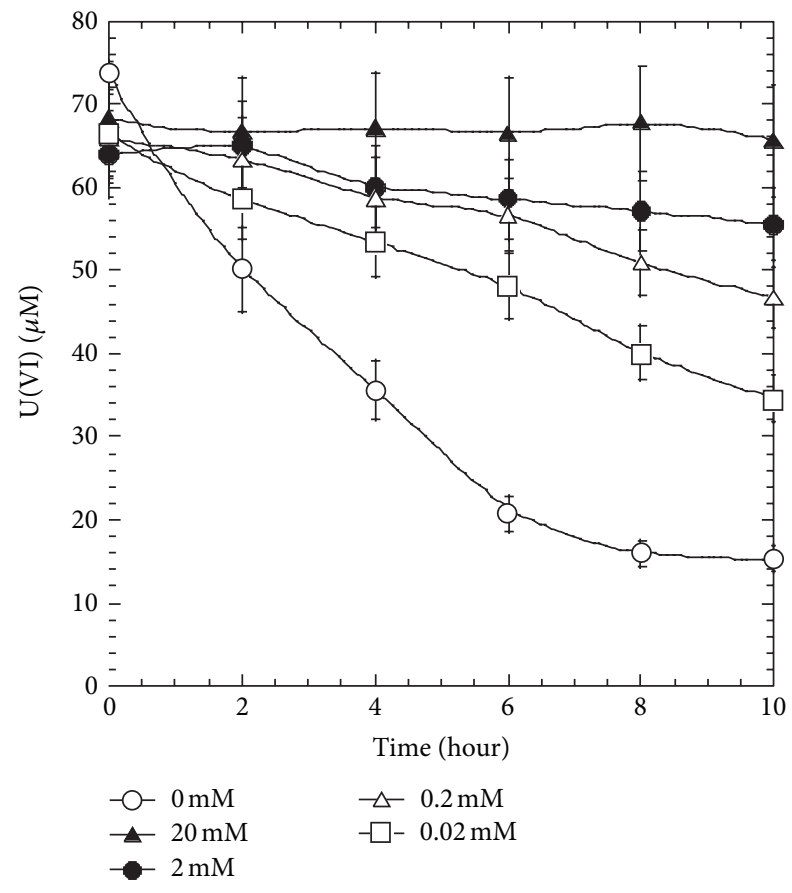

FIGURE 5: Effect of addition of Copper(II) on uranium reduction by Clostridium sp. BC1.

our experiments showed that the $\mathrm{pH}$ of the cultures could drop to 3 to 4 when the late-log phase of growth was reached; then, only the Clostridium sp. culture reduced $\mathrm{U}(\mathrm{VI})$ to U(IV) well, while the other three strains could not do so, or performed poorly [17]. In this study, we demonstrated that Clostridium sp. was superior in terms of growth and gas production. Thus, it seems reasonable to attribute the poorer performance of strains other than Clostridium sp. $\mathrm{BC} 1$ in $\mathrm{U}(\mathrm{VI})$ reduction to suboptimal growth. Meanwhile, our findings also exemplified that Clostridium sp. has higher tolerance to harsh environmental conditions, such as low $\mathrm{pH}$, as well as a stronger ability for fermentation under such conditions, especially in reducing $\mathrm{U}(\mathrm{VI})$ in acidic environments. Since this strain was isolated from an acidic metal-contaminated site [25], its better adaptation to acidic environments is unsurprising.

However, adding the $\mathrm{pH}$ buffer to cultures of C. sphenoides caused no improvement in its growth. Nevertheless, the reduction rate of $\mathrm{U}(\mathrm{VI})$ by this strain was much better at a near-neutral $\mathrm{pH}$, and its highest rate mostly closely approached that of Clostridium sp. [17]. Thus, an optimal $\mathrm{pH}$ alone apparently is important to $\mathrm{U}(\mathrm{VI})$ reduction by clostridia, even though it does not necessarily improve fermentation efficiency at the same time. We found that a suboptimal $\mathrm{pH}$ could compromise the ability of clostridia to reduce $\mathrm{U}(\mathrm{VI})$ : we suggest that the underlying mechanism for this phenomenon is as follows. Since most physiological reactions ideally occur at near-neutral $\mathrm{pH}$, organisms developed a variety of mechanisms to maintain a nearneutral cytoplasmic $\mathrm{pH}$. Even those acidophilic bacteria that grow best at $\sim \mathrm{pH} 3$ maintain a near-neutral cytoplasmic $\mathrm{pH}$ and possess a membrane potential $(\Delta \Psi)$ with an orientation reversed from that found in neutrophilic bacteria [26]. For gram-positive bacteria, including Clostridia, proton efflux through proton pumps, such as $\mathrm{F}_{1} \mathrm{~F}_{0}$ ATPase, is the major means of raising internal $\mathrm{pH}$ [27]. Goodwin and Zeikus [28] demonstrated that physiological adaptations of anaerobic bacteria to low $\mathrm{pH}$ often are a competitive process for hydrogen production. Thus, we speculate that the physiological adaptations of clostridia to suboptimal $\mathrm{pH}$ also compete with $\mathrm{U}(\mathrm{VI})$ reduction. Under suboptimal conditions, the bacterial response to the stressful environments becomes their priority, 


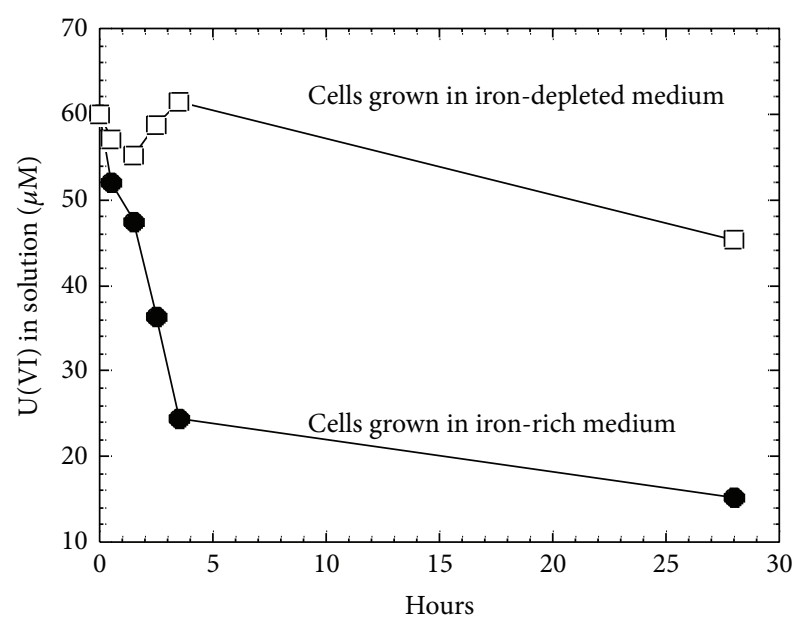

(a)

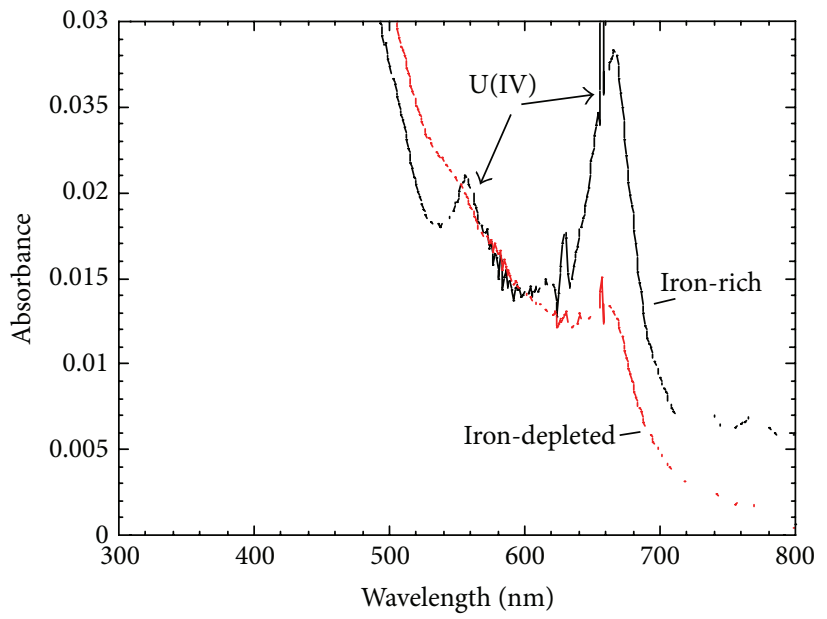

(b)

FIgure 6: Iron deficiency affects U(VI) reduction by Clostridium sp. BC1. (a) Dynamic curve of U(VI) reduction; (b) UV-vis visualization of reduced $\mathrm{U}(\mathrm{IV})$.

and more energy than normal is consumed in activities, such as amino acid metabolism, transcriptional regulation and signal transduction, transport, maintaining cell-membrane structure, and protection against oxidative stress, as was suggested by a transcriptome analysis of Shewanella oneidensis cells exposed to acidic and alkaline pHs [29]. Meanwhile, under the same conditions, other activities become secondary ones, such as $\mathrm{U}(\mathrm{VI})$ reduction, and little energy is allocated to them.

The mechanisms of uranium(VI) reduction by anaerobic respiratory bacteria, including Desulfovibrio, Geobacter, and Shewanella, are being extensively investigated $[5,6]$. However, although uranium reduction by Clostridia is established, the mechanisms underlying the reaction remain unclear. Our previous results showed that it was an enzymatic process since it happened only in the presence of growing or resting cells; neither the organic-acid metabolites generated nor the extracellular components of the culture, nor heatkilled cells could reduce uranium anaerobically [14]. Previous conjectures were that the reducing power generated from fermentation, such as that of glucose, caused uranium reduction. Thus, Petrie at al. [18] demonstrated that glucose amendments of the growth medium enriched the numbers of gram-positive spore-forming bacteria, and since some of the highest rates of $\mathrm{U}(\mathrm{VI})$ reduction in situ occurred upon amendment, that fermentative processes were involved [30]. Our previous study showed that the optimizing conditions for fermentation resulted in better $\mathrm{U}(\mathrm{VI})$ reduction support this hypothesis. Indeed, improving fermentation conditions by supplementing the medium with a $\mathrm{pH}$ buffer increased the $\mathrm{U}(\mathrm{VI})$ reduction rate of Clostridia strains [17]. Apparently, the efficiency of fermentation is positively related to the $\mathrm{U}(\mathrm{VI})$ reduction rate of individual strains.

In this study, we demonstrate that the hydrogen metabolism could play an important role in both uranium(VI) and iron(III) reduction by Clostridium sp. When hydrogen gas $\left(\mathrm{H}_{2}\right)$ was provided in the headspace of the serum bottle, either uranium(VI) or iron(III) reduction occurred in the presence of whole cells without carbon source. This is in contrast to the introduction of nitrogen gas $\left(\mathrm{N}_{2}\right)$ into the headspace. In the absence of whole cells, hydrogen alone could result neither uranium(VI) nor iron(III) reduction, suggesting that a hydrogenase mediated both the uranium(VI) and iron(III) reduction using hydrogen as the electron donor (Figure 4). Evidence supporting this hypothesis also came from $\mathrm{Cu}(\mathrm{II})$ inhibition effects on uranium reduction of clostridia (Figure 5). Since $\mathrm{Cu}(\mathrm{II})$ is a documented hydrogenase inhibitor [31], the inhibition of $\mathrm{U}(\mathrm{VI})$ reduction is most likely through the inhibition of hydrogenase activity of Clostridia cells. Hydrogenase mediated metal reduction also occurred in anaerobic metal respiring bacteria [32]. Our experiment also showed that Clostridium cells cultured in iron deficient media compromised its capability for uranium reduction (Figure 6). It is also noteworthy that the deficiency in ferrous ions also affected hydrogen production (data not shown). Still, our recent results showing that methyl viologen (MV) addition affects hydrogenase activity with a significant reduction in hydrogen production also agree with this hypothesis [33]. Taken together, one scenario explaining molecular mechanisms of uranium(VI) reduction by clostridia is emerging and is described as below.

Clostridia dispose of excess electrons generated during fermentation by producing hydrogen. During the fermentation process, bacteria that grow at the expense of diverse carbon sources often depend on ferredoxin or flavodoxin for essential oxidation-reduction reactions [34]. The metabolic pathway of hydrogen production in clostridia is summarized in Figure 7.

As shown in Figure 7, Clostridia use ferredoxin (Fd) to oxidize sugars and other organic matter through pyruvate to produce carbon dioxide, acetate, and butyrate. Ferredoxins are acidic, low molecular weight, soluble iron-sulfur proteins found in various organisms and act as multifunctional 


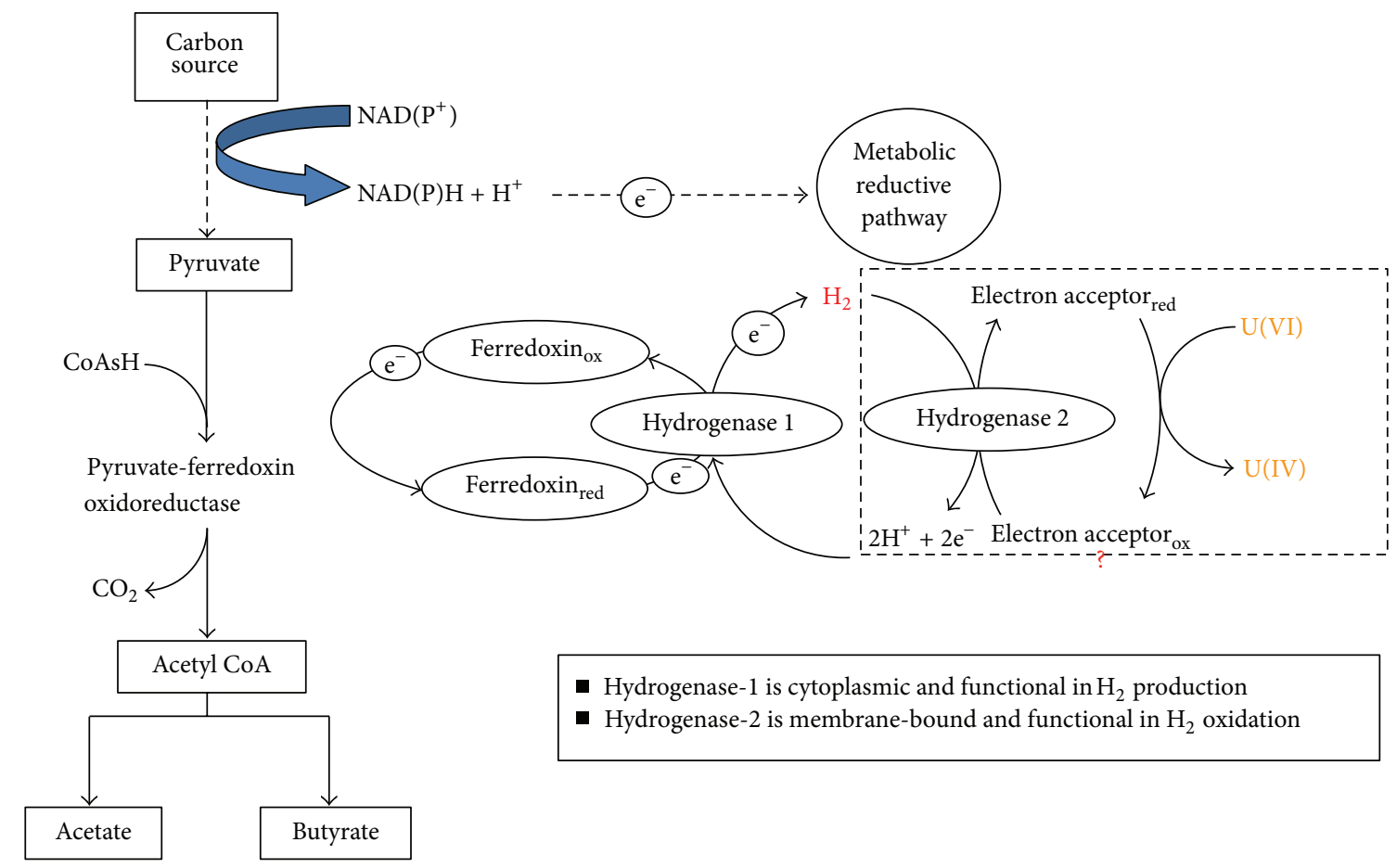

Figure 7: A hypothetic scheme illustrating clostridia fermentation pathway leading to hydrogen production and its roles in uranium reduction.

electron carriers in diverse redox systems [34]. Flavodoxin can replace ferredoxin in most of the reactions. Flavodoxin is a flavin mononucleotide-binding redox protein with an open twisted alpha/beta structure consisting of five parallel beta-sheets connected by alpha-helices which surround the sheets in the 3D structure. Ferredoxins or flavodoxins are essential components of the electron transport chains of clostridia. However, they do not themselves possess enzymatic activity in these reactions. Instead, they interact with specific dehydrogenases and reductases that handle the substrates to be oxidized or reduced. Hydrogenase, a molecular hydrogen evolving enzyme, receives electrons from pyruvate oxidation through up to seven Fd clusters to produce hydrogen $\left(\mathrm{H}_{2}\right)$ by the reaction as follows: $2 \mathrm{H}^{+}$ $+2 \mathrm{e}^{-} \leftrightarrow \mathrm{H}_{2}$ [1]. In some strains of clostridia, the presence of nitrogenase complicated hydrogen metabolism. In the presence of nitrogen and absence of ammonia, nitrogenases catalyze the production of hydrogen and ammonia at the expense of ATP. Without nitrogen, nitrogenases can function as $100 \%$ hydrogenase to produce hydrogen in a process that requires ATP and electrons from biomass.

The molecular basis for biological hydrogen production is dependent upon the presence of hydrogen-producing enzymes. At present, there are three known enzymes carrying out such reactions: Fe-hydrogenase, Ni-Fe hydrogenase, and nitrogenase. Iron-hydrogenase was first isolated from Clostridium pasteurianum [10]. It is also found in other strict anaerobic bacteria such as Desulfovibrio vulgaris [35, 36], as well as in some green algae such as Chlamydomonas reinhardtii [37], and several eukaryotic protists such as Trichomonas vaginalis [38]. A Fe-hydrogenase may exist as a distinct monomer or heteromer [39]. Generally, the cytoplasmic Fe-hydrogenase (Hydrogenase-1) functions as the generator of hydrogen by removing excess reducing equivalents during fermentations of strict anaerobic bacteria, whereas the periplasmic Fe-hydrogenase (Hydrogenase2) functions in hydrogen oxidation [40]. Fe-hydrogenase contains a unique complex Fe-S centers in which one of the $\mathrm{Fe}$ atoms is complexed with $\mathrm{CO}$ and $\mathrm{CN}$ [41]. Compared with nitrogenase and $\mathrm{Ni}$-Fe hydrogenase, Fe-hydrogenase is highly efficient in hydrogen production.

As shown in Figure 7, we postulate that both Hydrogenases 1 and 2 are involved in uranium reduction of clostridia. While Hydrogenase 1 functions as the generator of hydrogen by removing excess reducing equivalents during fermentations, Hydrogenase 2 functions in hydrogen oxidation and more directly involved in uranium reduction. It is not clear how the hydrogenases of clostridia consume hydrogen and transfer electrons to iron(III) or uranium(VI). In addition to hydrogenase, it is not known if additional proteins are involved in this process. One of such other possible candidates conducting direct electron transfer is cytochrome protein. Cytochromes are generally membranebound proteins that contain heme groups and carry out electron transport. Many cytochromes (c-type, b-type) of dissimilatory metal reducing bacteria (DMRB) were shown to be relevant to metal reduction $[42,43]$. The presence of cytochrome in clostridia has been documented previously 
[44]. From the annotated genome sequence of Clostridium acetobutylicum (ATCC 824) [24], around 30 cytochrome-like proteins have been identified. We also postulate that iron depletion could result in the shutdown or downregulation of hydrogenase synthesis as well as other iron-containing proteins like ferredoxin. Meanwhile, as a substitution, the expression of some noniron proteins such as flavodoxin could be upregulated. Due to this shift in protein synthesis, clostridia compromise their metabolism of hydrogen production, as well as their capability for uranium reduction. Note that our proposed model herein does not necessarily exclude possible other pathways and other components also used by Clostridia for uranium reduction, such as spore-mediated metal reduction [45].

\section{Final Remarks}

With their widespread occurrence in soils, sediments, and low-level radioactive wastes, Clostridia could play a significant role in the in situ reduction of uranium and other metals particularly at acidic $\mathrm{pH}$ and in nitrate-rich environments, as suggested by a number of studies $[18,20,21,25$, 30]. However, compared with anaerobic respiratory bacteria including Desulfovibrio, Geobacter, and Shewanella, molecular mechanisms underpinning uranium(VI) reduction to uranium(IV) are still not very clear. Future study toward this direction should be encouraged and we expect more detailed mechanisms of uranium reduction by Clostridia will be revealed in the future.

\section{Acknowledgments}

The authors thank Cleveland J. Dodge for assistance in this study and Avril D. Woodhead for editorial help. This research was supported by the Office of Biological and Environmental Research, Office of Science, U. S. Department of Energy, under Contract no. DE-AC02-98CH10886 and in part by the World Class University (WCU) program through the National Research Foundation of Korea funded by the Ministry of Education, Science and Technology (R31-30005).

\section{References}

[1] E. Cardenas, W. M. Wu, B. M. Leigh et al., "Significant association between sulfate-reducing bacteria and uranium-reducing microbial communities as revealed by a combined massively parallel sequencing-indicator species approach," Applied and Environmental Microbiology, vol. 76, no. 20, pp. 6778-6786, 2010.

[2] Y. Liang, J. D. Van Nostrand, L. A. N'guessan et al., "Microbial functional gene diversity with a shift of subsurface redox conditions during in situ uranium reduction," Applied and Environmental Microbiology, vol. 76, no. 20, pp. 6778-6786, 2012.

[3] J. D. Van Nostrand, L. Wu, W. M. Wu et al., "Dynamics of microbial community composition and function during in situ bioremediation of a uranium-contaminated aquifer," Applied and Environmental Microbiology, vol. 77, no. 11, pp. 3860-3869, 2011.
[4] J. C. Renshaw, L. J. C. Butchins, F. R. Livens, I. May, J. M. Charnock, and J. R. Lloyd, "Bioreduction of uranium: environmental implications of a pentavalent intermediate," Environmental Science and Technology, vol. 39, no. 15, pp. 56575660, 2005.

[5] J. D. Wall and L. R. Krumholz, "Uranium reduction," Annual Review of Microbiology, vol. 60, pp. 149-166, 2006.

[6] M. J. Wilkins, F. R. Livens, D. J. Vaughan, and J. R. Lloyd, "The impact of Fe(III)-reducing bacteria on uranium mobility," Biogeochemistry, vol. 78, no. 2, pp. 125-150, 2006.

[7] S. B. Leschine, "Cellulose degradation in anaerobic environments," Annual Review of Microbiology, vol. 49, pp. 399-426, 1995.

[8] D. R. Woods, "The genetic engineering of microbial solvent production," Trends in Biotechnology, vol. 13, no. 7, pp. 259-264, 1995.

[9] J. G. Zeikus, "Chemical and fuel production by anaerobic bacteria," Annual Review of Microbiology, vol. 34, pp. 423-464, 1980.

[10] J. S. Chen and J. L. Johnson, "Molecular biology of nitrogen fixation in the clostridia," Biotechnology, vol. 25, pp. 371-392, 1993.

[11] H. G. Wood and L. G. Ljungdahl, "Autotrophic character of acetogenic bacteria," in Variations in Autotrophic Life, J. M. Shively and L. L. Barton, Eds., pp. 201-250, Academic Press, San Diego, Calif, USA, 1991.

[12] A. Karnholz, K. Küsel, A. Gößner, A. Schramm, and H. L. Drake, "Tolerance and metabolic response of acetogenicbacteria toward oxygen," Applied and Environmental Microbiology, vol. 68, pp. 1005-1009, 2002.

[13] K. Küsel, A. Karnholz, T. Trinkwalter, R. Devereux, G. Acker, and H. L. Drake, "Physiological ecology of Clostridium glycolicum RD-1, an aerotolerant acetogen isolated from sea grass roots," Applied and Environmental Microbiology, vol. 67, no. 10, pp. 4734-4741, 2001.

[14] A. J. Francis, C. J. Dodge, F. Lu, G. P. Halada, and C. R. Clayton, "XPS and XANES studies of uranium reduction by Clostridium sp.," Environmental Science Technology, vol. 28, no. 4, pp. 636639, 1994.

[15] A. J. Francis, C. J. Dodge, and G. E. Meinken, "Biotransformation of pertechnetate by Clostridia," Radiochimica Acta, vol. 90, no. 9-11, pp. 791-797, 2002.

[16] A. J. Francis, G. Joshi-T, C. J. Dodge, and J. B. Gillow, "Biotransformation of uranium and transition metal citrate complexes by Clostridia," Journal of Nuclear Science and Technology, vol. 3, supplement, pp. 935-938, 2002.

[17] W. Gao and A. J. Francis, "Reduction of uranium(VI) to (IV) by Clostrdia," Applied and Environmental Microbiology, vol. 74, pp. 4580-4584, 2008.

[18] L. Petrie, N. N. North, S. L. Dollhopf, D. L. Balkwill, and J. E. Kostka, "Enumeration and characterization of iron(III)reducing microbial communities from acidic subsurface sediments contaminated with uranium(VI)," Applied and Environmental Microbiology, vol. 69, no. 12, pp. 7467-7479, 2003.

[19] Y. Suzuki, S. D. Kelly, K. M. Kemner, and J. F. Banfield, "Microbial populations stimulated for hexavalent uranium reduction in uranium mine sediment," Applied and Environmental Microbiology, vol. 69, no. 3, pp. 1337-1346, 2003.

[20] W. Dong, G. Xie, T. R. Miller et al., "Sorption and bioreduction of hexavalent uranium at a military facility by the Chesapeake Bay," Environmental Pollution, vol. 142, no. 1, pp. 132-142, 2006. 
[21] A. S. Madden, A. C. Smith, D. L. Balkwill, L. A. Fagan, and T. J. Phelps, "Microbial uranium immobilization independent of nitrate reduction," Environmental Microbiology, vol. 9, no. 9, pp. 2321-2330, 2007.

[22] A. J. Francis and C. J. Dodge, "Anaerobic microbial dissolution of transition and heavy metal oxides," Applied and Environmental Microbiology, vol. 54, pp. 1009-1014, 1988.

[23] E. R. Weyer and L. F. Rettger, "A comparative study of six different strains of the organism commonly concerned in largescale production of butyl alcohol and acetone by the biological process," Journal of Bacteriology, vol. 14, pp. 399-424, 1927.

[24] J. Nölling, G. Breton, M. V. Omelchenko et al., "Genome sequence and comparative analysis of the solvent-producing bacterium Clostridium acetobutylicum," Journal of Bacteriology, vol. 183, no. 16, pp. 4823-4838, 2001.

[25] A. J. Francis, S. Dobbs, and B. J. Nine, "Microbial activity of trench leachates from shallow-land, low-level radioactive waste disposal sites," Applied and Environmental Microbiology, vol. 40, no. 1, pp. 108-113, 1980.

[26] J. C. Cox, D. G. Nicholls, and W. J. Ingledew, "Transmembrane electrical potential and transmembrane $\mathrm{pH}$ gradient in the acidophile Thiobacillus ferrooxidans," Biochemical Journal, vol. 178, no. 1, pp. 195-200, 1979.

[27] P. D. Cotter and C. Hill, "Surviving the acid test: responses of gram-positive bacteria to low $\mathrm{pH}$," Microbiology and Molecular Biology Reviews, vol. 67, no. 3, pp. 429-453, 2003.

[28] S. Goodwin and J. G. Zeikus, "Physiological adaptations of anaerobic bacteria to low $\mathrm{pH}$ : metabolic control of proton motive force in Sarcina ventriculi," Journal of Bacteriology, vol. 169, no. 5, pp. 2150-2157, 1987.

[29] A. B. Leaphart, D. K. Thompson, K. Huang et al., "Transcriptome profiling of Shewanella oneidensis gene expression following exposure to acidic and alkaline $\mathrm{pH}$," Journal of Bacteriology, vol. 188, no. 4, pp. 1633-1642, 2006.

[30] J. D. Istok, J. M. Senko, L. R. Krumholz et al., "In situ bioreduction of technetium and uranium in a nitrate-contaminated aquifer," Environmental Science and Technology, vol. 38, no. 2, pp. 468-475, 2004.

[31] V. M. Fernandez, M. L. Rua, P. Reyes, R. Cammack, and E. C. Hatchikian, "Inhibition of Desulfovibrio gigas hydrogenase with copper salts and other metal ions," European Journal of Biochemistry, vol. 185, no. 2, pp. 449-454, 1989.

[32] D. A. Elias, J. M. Suflita, M. J. McInerney, and L. R. Krumholz, "Periplasmic cytochrome $\mathrm{c} 3$ of desulfovibrio vulgaris Is directly involved in $\mathrm{H}_{2}$-mediated metal but not sulfate reduction," Applied and Environmental Microbiology, vol. 70, no. 1, pp. 413420, 2004.

[33] V. N. Yarlagadda, A. Gupta, C. J. Dodge, and A. J. Francis, "Effect of exogenous electron shuttles on growth and fermentative metabolism in Clostridium sp. BCl," Bioresource Technology, vol. 108, pp. 295-299, 2012.

[34] L. E. Mortenson, "Purification and analysis of ferredoxin from Clostridium pasteurianum," Biochimica et Biophysica Acta, vol. 81, no. 1, pp. 71-77, 1964.

[35] G. Voordouw and S. Brenner, "Nucleotide sequence of the gene encoding the hydrogenase from Desulfovibrio vulgaris (Hildenborough)," European Journal of Biochemistry, vol. 148, no. 3, pp. 515-520, 1985.

[36] G. Voordouw, J. D. Strang, and F. R. Wilson, "Organization of the genes encoding [Fe] hydrogenase in Desulfovibrio vulgaris," Journal of Bacteriology, vol. 171, no. 7, pp. 3881-3889, 1989.
[37] T. Happe, B. Mosler, and J. D. Naber, "Induction, localization and metal content of hydrogenase in the green alga Chlamydomonas reinhardtii," European Journal of Biochemistry, vol. 222, no. 3, pp. 769-774, 1994.

[38] M. J. Payne, A. Chapman, and R. Cammack, "Evidence for an [Fe]-type hydrogenase in the parasitic protozoan Trichomonas vaginalis," FEBS Letters, vol. 317, no. 1-2, pp. 101-104, 1993.

[39] M. C. Posewitz, P. W. King, S. L. Smolinski, L. Zhang, M. Seibert, and M. L. Ghirardi, "Discovery of two novel radical Sadenosylmethionine proteins required for the assembly of an active [Fe] hydrogenase," Journal of Biological Chemistry, vol. 279, no. 24, pp. 25711-25720, 2004.

[40] M. W. W. Adams, "The structure and mechanism of ironhydrogenases," Biochimica et Biophysica Acta, vol. 1020, no. 2, pp. 115-145, 1990.

[41] J. W. Peters, "X-ray crystal structure of the Fe-only hydrogenase $(\mathrm{Cpl})$ from Clostridium pasteurianum to 1.8 angstrom resolution," Science, vol. 282, no. 5395, pp. 1853-1858, 1998.

[42] M. J. Marshall, A. E. Plymale, D. W. Kennedy et al., "Hydrogenase- and outer membrane c-type cytochromefacilitated reduction of technetium(VII) by Shewanella oneidensis MR-1," Environmental Microbiology, vol. 10, no. 1, pp. 125-136, 2008.

[43] L. Shi, D. J. Richardson, Z. Wang et al., "The roles of outer membrane cytochromes of Shewanella and Geobacter in extracellular electron transfer," Environmental Microbiology Reports, vol. 1, no. 4, pp. 220-227, 2009.

[44] M. Gottwald, J. R. Andreesen, J. LeGall, and L. G. Ljungdahl, "Presence of cytochrome and menaquinone in Clostridium formicoaceticum and Clostridium thermoaceticum," Journal of Bacteriology, vol. 122, no. 1, pp. 325-328, 1975.

[45] E. D. Vecchia, H. Veeramani, E. I. Suvorova, N. S. Wigginton, J. R. Bargar, and R. Bernier-Latmani, "U(VI) reduction by spores of Clostridium acetobutylicum," Research in Microbiology, vol. 161, no. 9, pp. 765-771, 2010. 

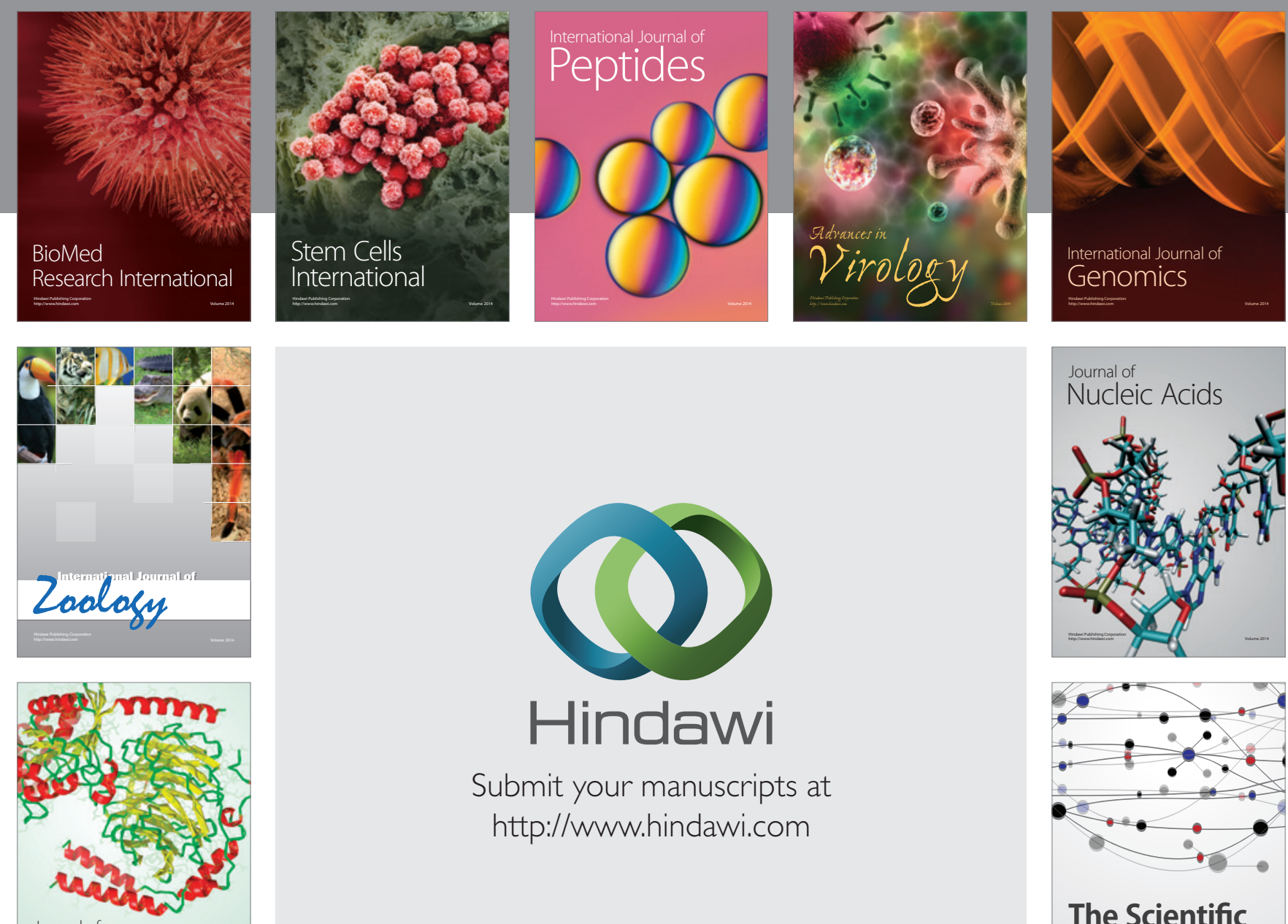

Submit your manuscripts at

http://www.hindawi.com

Journal of
Signal Transduction
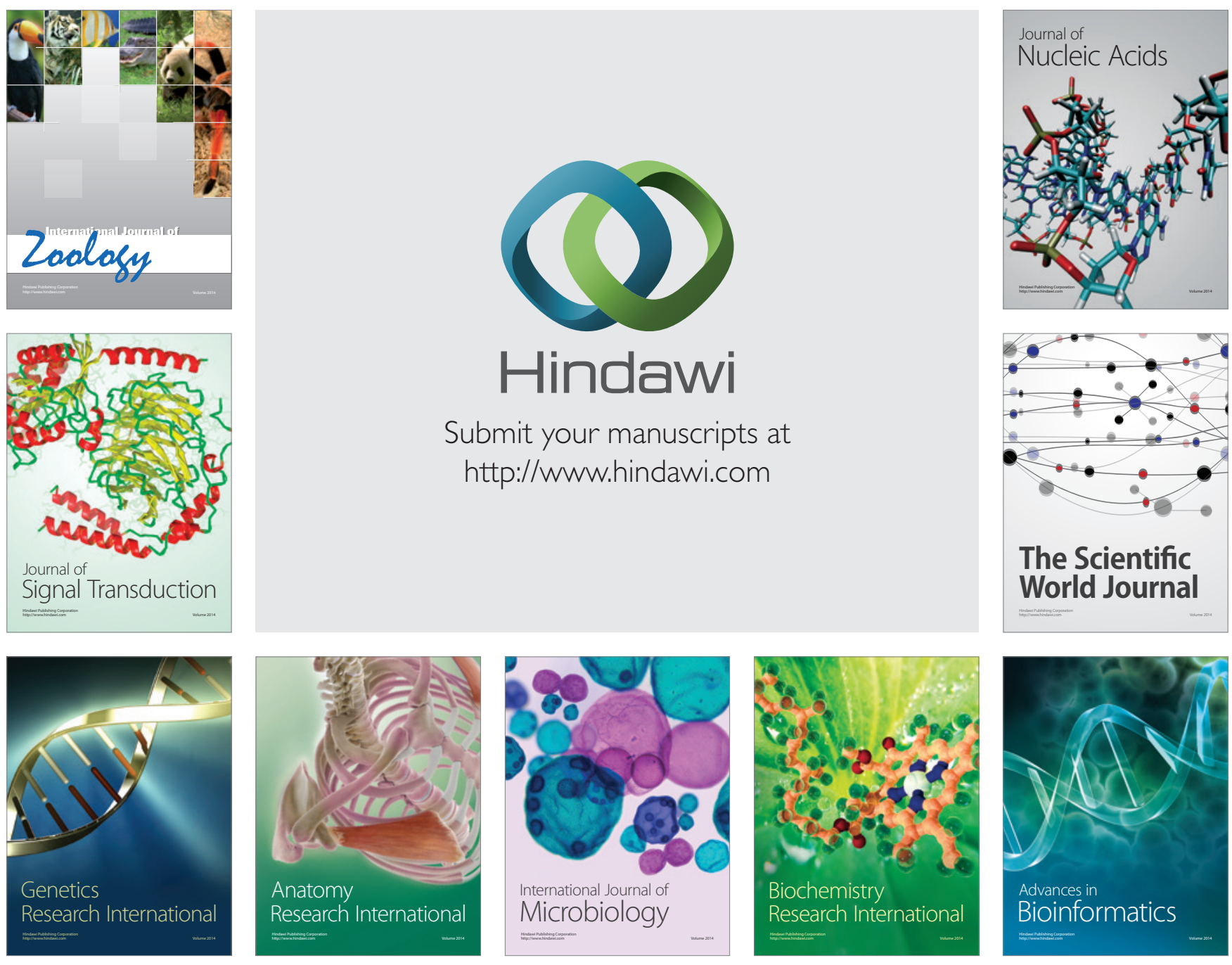

The Scientific World Journal
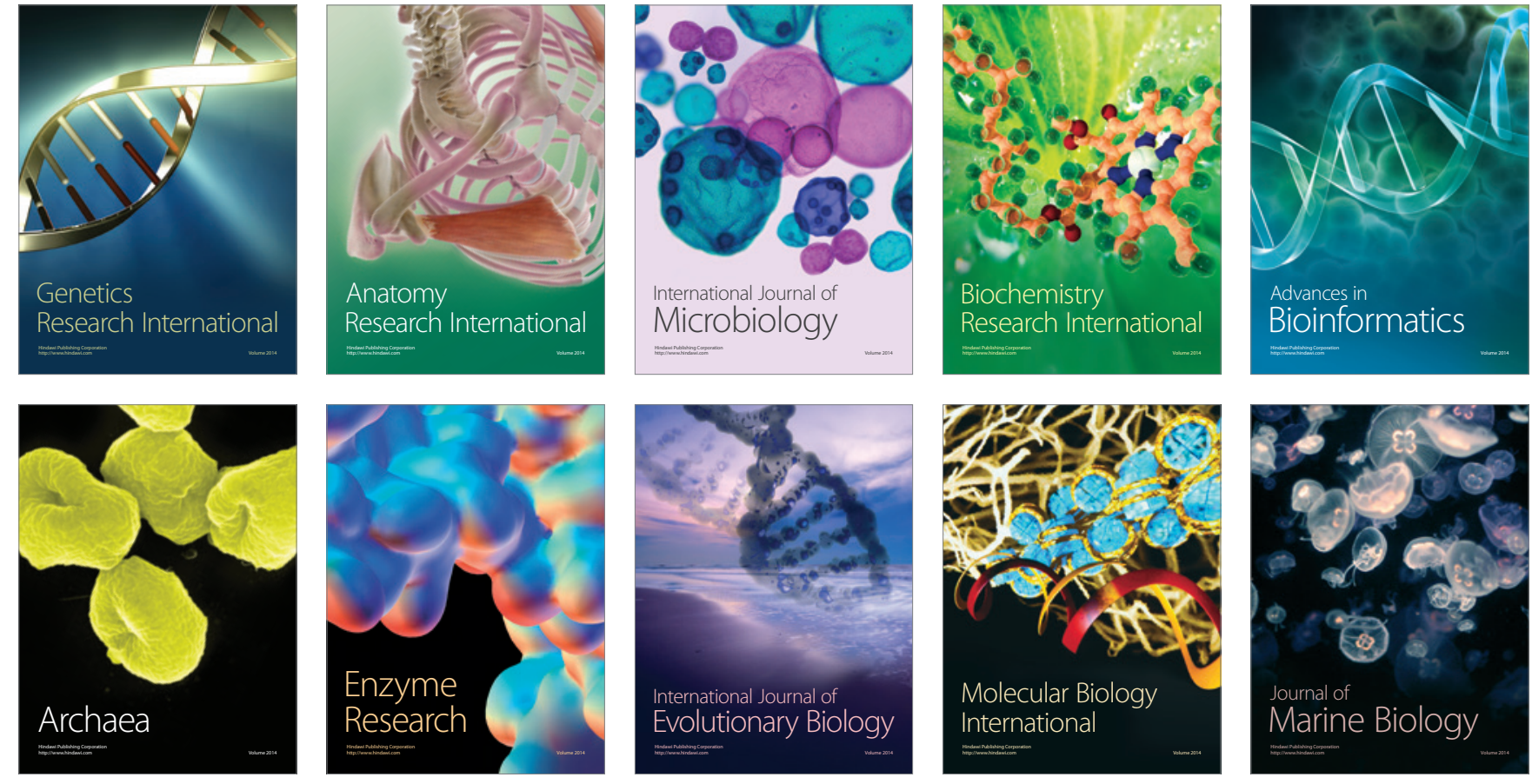